\title{
Mathematical Simulation of Heat and Mass Transfer Processes at the Ignition of Liquid Fuel by Concentrated Flux of Radiation
}

\author{
Olga V. Vysokomornaya, Genii V. Kuznetsov, and Pavel A. Strizhak \\ National Research Tomsk Polytechnic University, 30 Lenin Avenue, Tomsk 634050, Russia \\ Correspondence should be addressed to Olga V. Vysokomornaya; vysokomornaja@tpu.ru
}

Received 29 April 2014; Accepted 10 July 2014; Published 24 July 2014

Academic Editor: Zhijun Zhang

Copyright ( 2014 Olga V. Vysokomornaya et al. This is an open access article distributed under the Creative Commons Attribution License, which permits unrestricted use, distribution, and reproduction in any medium, provided the original work is properly cited.

\begin{abstract}
The physical and forecasting mathematical models of heat and mass transfer with phase transformations and chemical reactions under heating and following ignition of typical liquid fuel by using concentrated flow of radiation were developed. The influence scales of energy absorption process by means of gas-vapor mixture and liquid on ignition characteristics were established. The ignition delay time dependencies on the concentrated luminous power and radius of its coverage were determined.
\end{abstract}

\section{Introduction}

The ever more difficult and important ignition triggering problems continuously arise under the conditions of continuous development and improvement of facilities and technologies associated with ignition and combustion processes. Primarily, the problems of designing an energy-efficient ignition system arise in the making of diverse power installation and special-purpose motors $[1,2]$ using different fuel types as the source of energy. The operational parameters of these installations and their performance reliability depend on the ignition system effectiveness.

There are [3] six energy delivery mechanisms concerning ignition of the condensed substances: (1) forced convection, (2) heat conduction, (3) heat radiation, (4) diffusion of metallic vapors subjected to condensation or active radical sightings of the igniter flame to fuel surface, (5) photochemical absorption, and (6) heat transfer by using solid and liquid particles heated to high temperatures; these particles create local ignition centers, when they hit the surface of condensed substance.

In practice, the ignition processes of condensed substances with radiation energy supply may be implemented using, primarily, the laser. Besides, the concentrated flows of light energy can be generated under the conditions of accidental focusing action and reflection of sun rays at glass pieces and metal surfaces.
To date, the results of theoretical and experimental investigations concerning ignition processes of liquid fuels by using such energy sources [4-6] have been published. The ignition regularities of liquid condensed substances (e.g., typical liquid fuels) were studied less. In particular, the ignition problem of liquid fuel under the conditions of energy absorption using product flow of liquid evaporation was not solved. This factor may play a great role when heated under conditions of natural convection and heat radiation. Such factors were not analyzed in the classical theory of ignition [7].

The purpose of this paper is a numerical investigation of interrelated physicochemical processes complex during heating and subsequent liquid fuel ignition by using focused flow of heat radiation.

\section{Problem Statement}

In the first approximation in order to solve the ignition problem (getting sufficiently rough assessed characteristics' values of investigated processes) the known analytical and experimental approaches for researching ignition processes of condensed substances by concentrated radiation flux (e.g., $[8,9])$ can be used. However, these approaches do not take into account the whole set of heat and mass transfer processes under conditions of intensive endothermic phase change and 


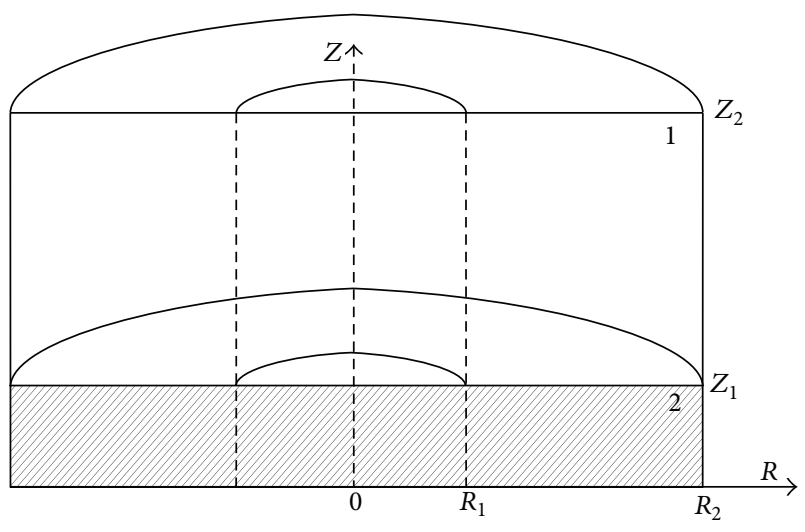

FIGURE 1: Schematic illustration of problem: 1: gas-vapor mixture, 2: liquid fuel.

chemical reaction. It was found [4-7] that heat and mass transfer processes are general at the heating and ignition stages of condensed substances. Thus, a full problem statement is reasonable at using mathematical physics equations.

The "laser flow-mixture of liquid fuel vapors with oxidizing agent" system illustrated in Figure 1 is considered.

It is assumed that the beam of focused laser radiation with $p$ (power) continuously affects the surface of a typical liquid fuel-kerosene. The radius of radiation coverage is $R_{1}$. The surface coats of liquid fuel are heated by means of radiation energy. Then liquid evaporation takes place. The forming fuel vapors react with oxidizing agent. Part of the energy is absorbed by a gas mixture while passing the laser beams. Ignition occurs when reaching the gas-vapor mixture critical temperature and the concentration of its components.

The considered ignition problem has been solved at 2D statement in cylindrical coordinate system. It was established [10] that 2D and 3D statements for local condensed substances ignition problems allow obtaining close values of ignition integral characteristics (the deviations are less than $6-8 \%$ ). Figure 1 shows the 2D statement with conventional representations of the coverage radiation radius and the solution area.

The numerical analysis of investigated process was carried out under the assumption (imposing no significant restrictions on the problem statement) that the one substance with known characteristics is formed as a result of flammable liquid evaporation. The effective activation energy values $E$, preexponential factor $k_{0}$, and thermal effect $Q_{o}$ are usually [11] defined in the experimental determination of kinetic parameters for oxidation reaction of liquid substances' vapors. The one "effective" chemical reaction involving one flammable substance was assumed. Accordingly, the theoretical analysis of the investigated process is possible at using kinetic scheme with known kinetic constants.

The potential burning of liquid fuel is not taken into consideration in the course of simulation. It is known [7] that the burning factor is visible only in the course of prolonged heating of substance (more than $5 \mathrm{~s}$ ). Role of this factor is insignificant at fast velocities of ignition (ignition delay time is less than $0.5 \mathrm{~s}$ ) [12].

There are three ignition criterions of condensed substances:

(1) zero gradient determination of temperatures on the "energy source-substance" boundary [13];

(2) the energy released by chemical reaction of fuel vapors with oxidizing agent that exceeds the energy transmitted from the source [7];

(3) sharp increase of temperature and burning in any point of substance [12].

It was assumed that ignition occurs at the moment when quantity of energy released during fuel vapors oxidation reaction exceeds quantity of energy transferred from the energy source to liquid fuel. This criterion is the most adequate to being simulated complex of processes.

\section{Mathematical Model}

The system of nonlinear nonstationary differential equations at $0<\tau<\tau_{d}$ includes the following.

Continuity equation of gas-vapor mixture $(0<R<$ $R_{2}, Z_{1}<Z<Z_{2}$ ):

$$
\frac{\partial^{2} \Psi}{\partial R^{2}}-\frac{1}{R} \frac{\partial \Psi}{\partial R}+\frac{\partial^{2} \Psi}{\partial Z^{2}}=-R \Omega
$$

motion equation of gas-vapor mixture $\left(0<R<R_{2}\right.$, $\left.Z_{1}<Z<Z_{2}\right)$ :

$$
\begin{aligned}
\frac{\partial \Omega}{\partial \tau} & +U \frac{\partial \Omega}{\partial R}+V \frac{\partial \Omega}{\partial Z} \\
& =\sqrt{\frac{\operatorname{Pr}_{1}}{\mathrm{Ra}_{1}}}\left[\frac{\partial^{2} \Omega}{\partial R^{2}}+\frac{1}{R} \frac{\partial \Omega}{\partial R}+\frac{\partial^{2} \Omega}{\partial Z^{2}}-\frac{\Omega}{R^{2}}\right]+\frac{\partial \Theta_{1}}{\partial R} ;
\end{aligned}
$$

energy equation for gas-vapor mixture in the laser coverage $\left(0<R<R_{1}, Z_{1}<Z<Z_{2}\right)$ :

$$
\begin{aligned}
\frac{\partial \Theta_{1}}{\partial \tau} & +U \frac{\partial \Theta_{1}}{\partial R}+V \frac{\partial \Theta_{1}}{\partial Z} \\
= & \frac{1}{\sqrt{\operatorname{Ra}_{1} \operatorname{Pr}_{1}}}\left[\frac{\partial^{2} \Theta_{1}}{\partial R^{2}}+\frac{1}{R} \frac{\partial \Theta_{1}}{\partial R}+\frac{\partial^{2} \Theta_{1}}{\partial Z^{2}}\right] \\
& +\frac{z_{2}}{C_{1}(T) \rho_{1}(T) \Delta T V_{m}}
\end{aligned}
$$

energy equation for gas-vapor mixture out of the laser coverage $\left(R_{1}<R<R_{2}, Z_{1}<Z<Z_{2}\right)$ :

$$
\begin{aligned}
& \frac{\partial \Theta_{1}}{\partial \tau}+U \frac{\partial \Theta_{1}}{\partial R}+V \frac{\partial \Theta_{1}}{\partial Z} \\
& =\frac{1}{\sqrt{\mathrm{Ra}_{1} \mathrm{Pr}_{1}}}\left[\frac{\partial^{2} \Theta_{1}}{\partial R^{2}}+\frac{1}{R} \frac{\partial \Theta_{1}}{\partial R}+\frac{\partial^{2} \Theta_{1}}{\partial Z^{2}}\right]+\frac{Q_{o} W_{o} z_{2}}{\Delta T V_{m}}
\end{aligned}
$$


diffusion equation of fuel vapors in the air $(0<R<$ $\left.R_{2}, Z_{1}<Z<Z_{2}\right)$ :

$$
\begin{aligned}
& \frac{\partial C_{f}}{\partial \tau}+U \frac{\partial C_{f}}{\partial R}+V \frac{\partial C_{f}}{\partial Z} \\
& \quad=\frac{1}{\mathrm{Sc}_{11}} \sqrt{\frac{\operatorname{Pr}_{11}}{\mathrm{Ra}_{11}}}\left[\frac{\partial^{2} C_{f}}{\partial R^{2}}+\frac{1}{R} \frac{\partial C_{f}}{\partial R}+\frac{\partial^{2} C_{f}}{\partial Z^{2}}\right]-\frac{z_{2} W_{o}}{\rho_{11}(T) V_{m}} ;
\end{aligned}
$$

balance equation $\left(0<R<R_{2}, Z_{1}<Z<Z_{2}\right)$ :

$$
C_{f}+C_{o}=1
$$

energy equation for liquid fuel in the laser coverage ( 0 $<R<R_{1}, 0<Z<Z_{1}$ ):

$$
\frac{1}{\mathrm{Fo}_{2}} \frac{\partial \Theta_{2}}{\partial \tau}=\frac{\partial^{2} \Theta_{2}}{\partial R^{2}}+\frac{1}{R} \frac{\partial \Theta_{2}}{\partial R}+\frac{\partial^{2} \Theta_{2}}{\partial Z^{2}}+\frac{z_{2}}{\lambda_{2}(T) \Delta T} \frac{\partial H(Z)}{\partial Z} ;
$$

energy equation for liquid fuel out of the laser coverage $\left(R_{1}<R<R_{2}, 0<Z<Z_{1}\right)$ :

$$
\frac{1}{\mathrm{Fo}_{2}} \frac{\partial \Theta_{2}}{\partial \tau}=\frac{\partial^{2} \Theta_{2}}{\partial R^{2}}+\frac{1}{R} \frac{\partial \Theta_{2}}{\partial R}+\frac{\partial^{2} \Theta_{2}}{\partial Z^{2}} .
$$

Equations (1) and (2) describe the pressure and velocity change in the system. Equations (3) and (4) characterize the temperature change in the mixture of fuel vapors and air in the zone of concentrated radiation flux coverage and outside this zone. Equation (5) describes the change of fuel vapor concentration in oxidizer. Equation (6) characterizes the ratio between fuel and air content in the vapor-gas (binary) mixture. Equations (7) and (8) describe the liquid fuel temperature change in the zone of concentrated radiation flux coverage and outside this zone.

Initial $(\tau=0)$ conditions are as follows:

$$
\begin{aligned}
& 0<R<R_{2}, \quad 0<Z<Z_{1}: \Theta_{2}=\Theta_{0} ; \\
& 0<R<R_{2}, \quad Z_{1}<Z<Z_{2}: \\
& \Theta_{1}=\Theta_{0}, \quad C_{f}=0, \quad \Omega=0, \quad \Psi=0 .
\end{aligned}
$$

Boundary conditions $\left(0<\tau<\tau_{d}\right)$ are as follows:

$$
\begin{gathered}
Z=0, \quad 0<R<R_{2}: \frac{\partial \Theta_{2}}{\partial Z}=0 ; \\
Z=Z_{1}, \quad 0<R<R_{1}: \\
\frac{\partial \Theta_{2}}{\partial Z}=\frac{\lambda_{1}(T)}{\lambda_{2}(T)} \frac{\partial \Theta_{1}}{\partial Z}-\frac{z_{2}}{\Delta T \lambda_{2}(T)} \\
\times\left[Q_{e} W_{e}-H\left(Z_{1}\right) \exp \left(-\frac{r^{2}}{r_{1}^{2}}\right)\right], \\
\Theta_{1}=\Theta_{2}, \quad \frac{\partial C_{f}}{\partial Z}=-\frac{W_{e} z_{2}}{\rho_{11}(T) D_{11}(T)}, \\
\frac{\partial \Psi}{\partial Z}=U, \quad-\frac{\partial \Psi}{\partial R}=V ;
\end{gathered}
$$

$$
\begin{aligned}
& Z=Z_{1}, \quad R_{1}<R<R_{2} \text { : } \\
& \frac{\partial \Theta_{2}}{\partial Z}=\frac{\lambda_{1}(T)}{\lambda_{2}(T)} \frac{\partial \Theta_{1}}{\partial Z}-\frac{z_{2}}{\Delta T \lambda_{2}(T)} Q_{e} W_{e}, \\
& \Theta_{1}=\Theta_{2}, \quad \frac{\partial C_{f}}{\partial Z}=-\frac{W_{e} z_{2}}{\rho_{11}(T) D_{11}(T)}, \\
& \frac{\partial \Psi}{\partial Z}=U, \quad-\frac{\partial \Psi}{\partial R}=V ; \\
& Z=Z_{2}, \quad 0<R<R_{2} \text { : } \\
& \frac{\partial \Theta_{1}}{\partial Z}=\frac{z_{2}}{\Delta T \lambda_{1}(T)} H\left(Z_{2}\right) \exp \left(-\frac{r^{2}}{r_{1}^{2}}\right), \\
& \frac{\partial C_{f}}{\partial Z}=0, \quad \frac{\partial \Psi}{\partial Z}=0, \quad \Psi=0 ; \\
& R=0, \quad 0<Z<Z_{1}: \frac{\partial \Theta_{2}}{\partial R}=0 ; \\
& R=0, \quad Z_{1}<Z<Z_{2} \text { : } \\
& \frac{\partial \Theta_{1}}{\partial R}=0, \quad \frac{\partial C_{f}}{\partial R}=0, \quad \frac{\partial \Psi}{\partial R}=0, \quad \Psi=0 ; \\
& R=R_{2}, \quad 0<Z<Z_{1}: \frac{\partial \Theta_{2}}{\partial R}=0 ; \\
& R=R_{2}, \quad Z_{1}<Z<Z_{2} \text { : } \\
& \frac{\partial \Theta_{1}}{\partial R}=0, \quad \frac{\partial C_{f}}{\partial R}=0, \quad \frac{\partial \Psi}{\partial R}=0, \quad \Psi=0,
\end{aligned}
$$

where $Q_{o}$ is the thermal effect by oxidation reaction of fuel vapors, $\mathrm{J} / \mathrm{kg} ; W_{o}$ is the mass oxidation velocity of fuel vapors in the air, $\mathrm{kg} /\left(\mathrm{m}^{3} \cdot \mathrm{s}\right) ; R, Z$ are the dimensionless analogs $r, z$ $\left(R=r / z_{2}, Z=z / z_{2}\right) ; \rho$ is the density, $\mathrm{kg} / \mathrm{m}^{3} ; C$ is the specific thermal capacity, $\mathrm{J} /(\mathrm{kg} \cdot \mathrm{K}) ; \Delta T$ is the differential temperature $\left(\Delta T=T_{m}-T_{0}\right), \mathrm{K} ; T_{m}$ is the temperature scale, $\mathrm{K} ; T_{0}$ is the initial temperature of liquid fuel and oxidizer, $\mathrm{K} ; V_{m}$ is the convection velocity scale of fuel vapors, $\mathrm{m} / \mathrm{s} ; \lambda$ is the heat conduction, $\mathrm{W} /(\mathrm{m} \cdot \mathrm{K}) ; \tau$ is the dimensionless time $(\tau=$ $\left.t / t_{m}\right) ; t$ is the time, $s ; t_{m}$ is the time scale, $s ; \tau_{d}$ is the dimensionless ignition delay time; $\Psi$ is the dimensionless analog of current function; $\Omega$ is the dimensionless analog of velocity vorticity vector; $U, V$ are the dimensionless velocity components of fuel vapors in projection onto $R, Z$ axis; $\mathrm{Ra}$ is the Raleigh number; $\Theta$ is the dimensionless temperature $\left(\Theta=T / T_{m}\right)$; Pr is the Prandtl number; Sc is the Schmidt number; $C_{f}$ is the mass concentration of fuel vapors in the gas-vapor mixture; $C_{o}$ is the mass concentration of oxidizer in the gas-vapor mixture; Fo is the Fourier number; $H(Z)$ is the heat-flow density of laser radiation, $\mathrm{W} / \mathrm{m}^{2} ; H\left(Z_{2}\right)$ is the heatflow density included into the gas-vapor mixture (conditional upon $Z=Z_{2}$ ), W/m $\mathrm{m}^{2} ; Q_{e}$ is the thermal effect of liquid fuel evaporation, $\mathrm{J} / \mathrm{kg} ; W_{e}$ is the mass velocity of evaporation, $\mathrm{kg} /\left(\mathrm{m}^{3} \cdot \mathrm{s}\right) ; D$ is the diffusion coefficient of fuel vapors in the 
air, $\mathrm{m}^{2} / \mathrm{s}$; index numbers: 1 is the gas-vapor mixture, 2 is the liquid fuel, and 11 is the fuel vapors.

The expressions for $W_{e}, W_{o}$, and $V_{m}$ and Ra, Pr, Fo, and Sc (dimensionless groups) are presented in [14-17].

The heat-flow density of laser radiation at the boundary of gas-vapor mixture (conditional upon $Z=Z_{2}$ ) was determined from the following formula:

$$
H\left(Z_{2}\right)=\frac{p}{\pi r_{1}^{2}},
$$

where $p$ is the beam power of laser, $\mathrm{W}$, and $r_{1}$ is the coverage radius of laser beam, $m$.

The change of heat-flow density in the gas-vapor mixture (conditional upon $Z_{1}<Z<Z_{2}$ ) was determined by BouguerLambert-Beer law:

$$
H(Z)=H\left(Z_{2}\right) \exp \left[-k_{\lambda 1}\left(z_{2}-z\right)\right]
$$

where $k_{\lambda 1}$ is the absorption coefficient of laser radiation using gas-vapor mixture, $\mathrm{m}^{-1}$.

The change of heat-flow density of laser radiation in the liquid fuel (conditional upon $0<Z<Z_{1}$ ) was determined similarly:

$$
H(Z)=H\left(Z_{1}\right) \exp \left[-k_{\lambda 2}\left(z_{1}-z\right)\right]
$$

where $k_{\lambda 2}$ is the absorption coefficient of laser radiation by liquid, $\mathrm{m}^{-1}$.

The transition to dimensionless variables was accomplished using the following scale sizes: $z_{2}$ : dimension of solution region $\left(z_{2}=0,1 \mathrm{~m}\right) ; t_{m}$ : time scale $\left(t_{m}=1 \mathrm{~s}\right) ; T_{m}$ : temperature scale $\left(T_{m}=1000 \mathrm{~K}\right) ; V_{m}$ : scale of convection velocity of fuel vapors nearby liquid fuel surface, $\mathrm{m} / \mathrm{s} ; p_{m}$ : laser power scale $\left(p_{m}=100 \mathrm{~W}\right) ; k_{\lambda 1 m}$ : absorption coefficient scale of laser radiation by gas-vapor mixture $\left(k_{\lambda 1 \mathrm{~m}}=30 \mathrm{~m}^{-1}\right)$; $k_{\lambda 2 m}$ : absorption coefficient scale of laser radiation by liquid $\left(k_{\lambda 1 \mathrm{~m}}=10^{5} \mathrm{~m}^{-1}\right)$.

The algorithm and the solution methods of (1)-(8) equation system with initial and boundary conditions are similar to the one utilized in [14-17].

The system of nonlinear nonstationary differential equations (1)-(8) with initial and boundary conditions was solved by the finite difference method [18]. Difference analogues of differential equations (1)-(8) were solved by locally onedimensional method [18]. Sweep method using a four-point implicit difference scheme [18] was applied for solving onedimensional difference equations. Simple iteration method [18] was used for nonlinear equations solving.

The reliability of the obtained numerical results was estimated by verification of the used difference schemes conservatism. The accuracy of the energy conservation law implementation in selected solution area was calculated (the heat supplied to the liquid fuel and gas mixture from radiation flux, the energy released by the oxidation reaction, the heat expended on liquid evaporation, and the energy accumulated in the gas and liquid mediums have been taken into account) [14-17].

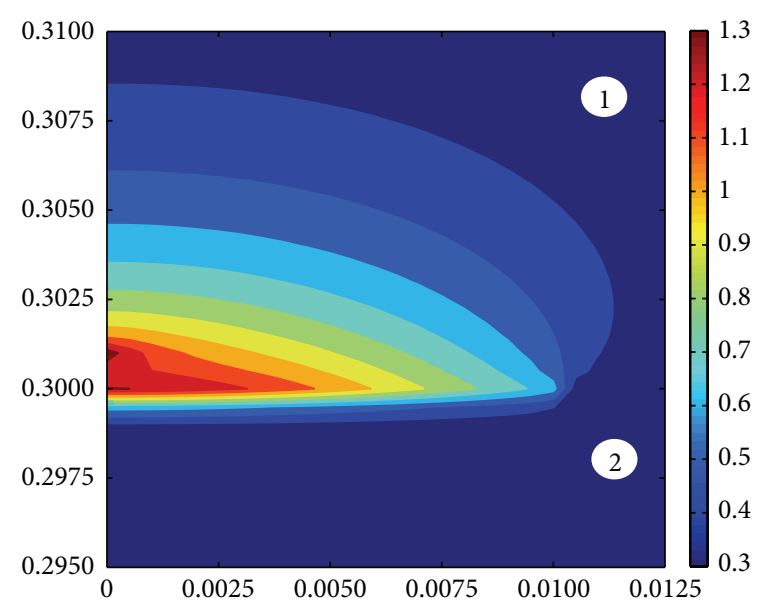

FIGURE 2: Isothermal curves of "concentrated flow of light emission-liquid-air" system at the moment of inflammation ( $\tau_{d}=1.483$ ) under the conditions of $P=0.4, R_{1}=0.08$.

\section{Results and Discussion}

Numerical simulation of ignition process in the system represented in Figure 1 was carried out using the following parameter values [19-23]: $T_{0}=300 \mathrm{~K}$, kerosene and air initial temperature; $Q_{o}=42 \mathrm{MJ} / \mathrm{kg}$, thermal effect by oxidation reaction of fuel vapors; $Q_{e}=261 \mathrm{~kJ} / \mathrm{kg}$, thermal effect of liquid fuel evaporation; $k_{0}=9 \cdot 10^{8} \mathrm{~s}^{-1}$, preexponential factor, and $E=193 \mathrm{~kJ} / \mathrm{mole}$, activation energy of oxidation reaction; $p=$ $30-100 \mathrm{~W}$, radiation power; $r_{1}=0,006 \mathrm{~m}$, coverage radius of radiation; $k_{\lambda 1}=1-30 \mathrm{~m}^{-1}$, absorption coefficient of radiation using gas-vapor mixture; $k_{\lambda 2}=10^{3}-10^{5} \mathrm{~m}^{-1}$, absorption coefficient of radiation using kerosene; $z_{1}=0,03 \mathrm{~m}$, film thickness of liquid fuel; $r_{2}=0,05 \mathrm{~mm}, z_{2}=0,1 \mathrm{~m}$, solution region dimension. Thermal and physical characteristics of liquid kerosene, its vapors, and air depending on the temperature were selected in accordance with [19-23].

It is found that several ignition stages being characterized by certain ranges of $\tau_{d}$ and localization point of oxidation chemical reaction zone can be implemented for "single small-sized particle heated up to high temperaturesliquid-oxidizing agent" systems depending on heat content of heating source and its contact relations with the liquid substance. There is only one ignition stage for the presented "concentrated flow of light emission-liquid-air" (Figure 1) system. The variation of heating source parameters results in a change of ignition characteristics (in particular, $\tau_{d}$ ), but the ignition zone is formed under all conditions only nearby evaporation boundary at the center of "heating spot" arisen at the surface of liquid fuel. The temperature field and the isothermal curves at the moment of inflammation $\left(\tau_{d}=1.483\right)$ under the conditions of $P=0.4, R_{1}=0.08$ are represented in Figure 2 to illustrate these objective laws.

Figure 2 shows that the depth of liquid heating is little. It is explained due to the higher coefficient of radiation energy adsorption by liquid fuel $\left(k_{\lambda 2}=0.68\right)$. The temperature gradients are maximum nearby the symmetry axes of coverage for light emission flow in close proximity to liquid phase 


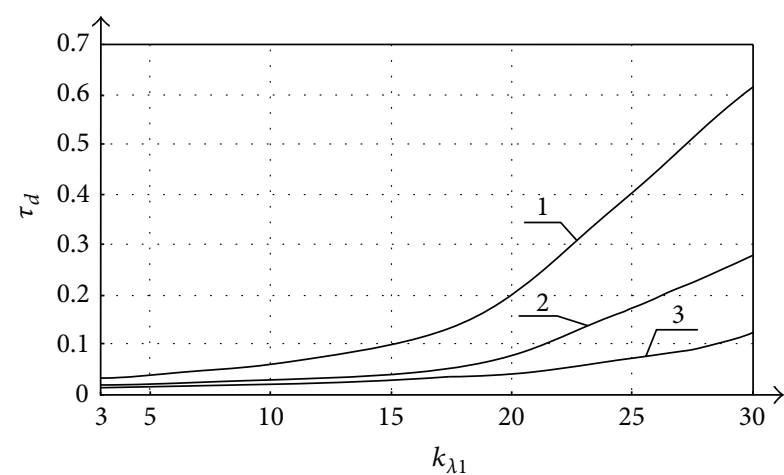

Figure 3: The dependence of the ignition delay time on the absorption coefficients of radiation using the gas-vapor mixture: 1 : under the condition of $P=0.6$; 2 : under the condition of $P=0.8 ; 3$ : under the condition of $P=1$.

transition boundary. It is conditional upon the simultaneous energy absorption during evaporation and the heat supply into the liquid from the light emission flow.

The absorption coefficients of radiation using gas-vapor mixture and liquid fuel were varied on a wide range $\left(k_{\lambda 1}=\right.$ $0.1-1, k_{\lambda 2}=10^{-2}-1$ ) for analyzing impact of energy absorption factors in relation to ignition characteristics during numerical simulation.

Figure 3 shows that the ignition delay time $\tau_{d}$ rises at absorption coefficient increase of radiation energy by gasvapor mixture $k_{\lambda 1}$. This unobvious result is caused by the cooperative behavior of the interrelated quite difficult heat and mass transfer processes. The decrease of radiation energy quantity supplied to the liquid and an increase of energy required for heating up of the being formed gas-vapor mixture take place at increase of $k_{\lambda 1}$. This should seem to lead to an acceleration of chemical reactions in the gas-vapor mixture and thus a decrease of ignition delay time. However, the increase of fuel vapors concentration near to the liquid surface is slowed down under such conditions. Therefore, the mass velocity of fuel evaporation is decreased. It leads to a decrease in velocities of chemical reactions and an increase in ignition delay time. The significant impact scales of $k_{\lambda 1}$ on $\tau_{d}$ ought to be noted (Figure 3; 1, 2 curves).

The analysis of Figures 4 and 5 shows that the ignition delay time significantly (more than fortyfold) increases under the conditions of a dimensionless power $(P)$ decrease and an action radius $\left(R_{1}\right)$ increase of laser radiation from 0.06 to 0.1 . The role of such factors as the absorption of radiation energy in the gas and liquid phases is increased under condition of ignition process time growth. Therefore, the impact scales of $k_{\lambda 1}$ on $\tau_{d}$ are sufficiently important. For instance, the impact scales of $k_{\lambda 1}$ on $\tau_{d}$ are significantly changed by varying the dimensionless radiation power in a range of $P=0.3-1$.

The liquid heating up and the being formed gas-vapor mixture processes are accelerated at the dimensionless radiation power $P$ increase. The role of radiation absorption factor by the gas-vapor mixture is sharply decreased (Figure 3, curve 3) under such conditions. The radiation energy is sufficient to warm up the liquid substance, to form the gas-vapor mixture,

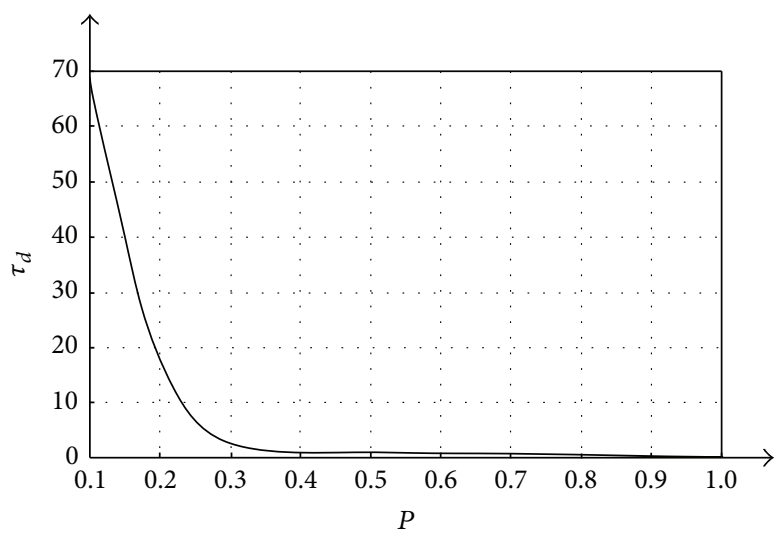

FIgure 4: The ignition delay time dependence on the radiation power under the condition of $R_{1}=0.06$ in "concentrated flow of light emission-liquid-air" system.

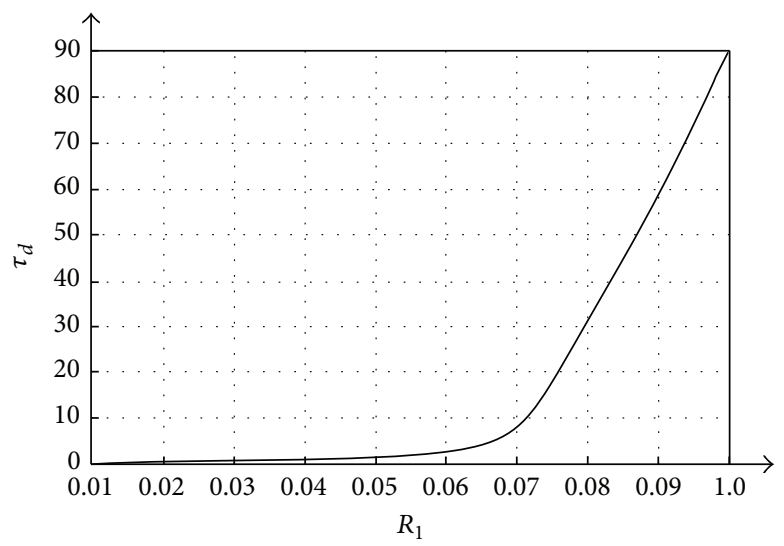

FIgURE 5: The ignition delay time dependence on the coverage radius of radiation under the condition of $P=0.3$ in "concentrated flow of light emission-liquid-air" system.

and to heat it up to limiting temperatures in sufficiently small time intervals (delay times are minimal).

Figure 6 shows that the $k_{\lambda 2}$ parameter has less visible effect on the ignition delay time of liquid fuel than the $k_{\lambda 1}$. The delay time is changed by less than $1 \%$ at the $k_{\lambda 2}$ varying in the range from $10^{-2}$ to 1 . This result shows that the regularities resting on the base of the model under consideration (Figure 1) for kerosene will pertain for a sufficiently large group of liquid combustible condensed substances.

The ignition delay time $\tau_{d}$ slightly (less than $1 \%$ ) increases with increasing the $k_{\lambda 2}$. The obtained dependence (Figure 6) can be explained by the fact that the depth of warmedup liquid layer rises slightly with increasing the absorption coefficient $k_{\lambda 2}$. The radiation energy is used for the liquid heating up and the evaporation from a large surface. As a consequence, the mass velocity from a surface unit is decreased. It leads to a slight increase of the ignition inertia. 


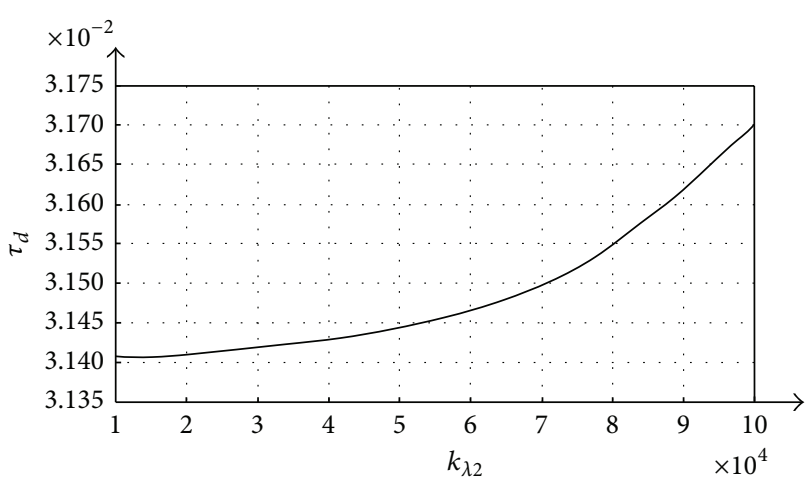

Figure 6: The ignition delay time dependence on the absorption coefficient of radiation by the liquid fuel.

\section{Conclusions}

The formulated physical and mathematical models can be used to investigate the complexes of interrelated heat and mass transfer processes at ignition of a large group of the liquid condensed substances by the concentrated radiation flow of different physical nature (laser, solar energy, and others). The observed particularities of ignition process associated with the absorption of radiation energy in the gas and liquid phases extend the understanding of classical ignition theory of the condensed substances [7]. The obtained simulation results in cooperation with [14-17] represent the base for creation of a general ignition theory of the condensed substances by the local sources of energy (metallic and nonmetallic particles, small wires, rods, concentrated radiation flows, and others).

\section{Conflict of Interests}

The authors declare that there is no conflict of interests regarding the publication of this paper.

\section{Acknowledgment}

The reported investigation was supported by grant of State Task "Nauka" (code of the Federal Target Scientific and Technical Program no. 2.1321.2014).

\section{References}

[1] D. K. Srivastava and A. K. Agarwal, "Comparative experimental evaluation of performance, combustion and emissions of laser ignition with conventional spark plug in a compressed natural gas fuelled single cylinder engine," Fuel, vol. 123, pp. 113-122, 2014.

[2] D. K. Srivastava, E. Wintner, and A. K. Agarwal, "Effect of focal size on the laser ignition of compressed natural gas-air mixture," Optics and Lasers in Engineering, vol. 58, pp. 67-79, 2014.

[3] R. P. McAlevy, P. L. Cowan, and M. Summerfield, "The mechanism of ignition of composite solid propellants by hot gases," ARS Progress in Astronautics and Rocketry: Solid Propellant Rocket Research, vol. 1, pp. 623-652, 2014.
[4] I. G. Assovskii and A. G. Istratov, "Propellant burning under light irradiation," Journal of Applied Mechanics and Technical Physics, vol. 5, p. 70, 1971.

[5] V. V. Medvedev, "Explosive decomposition of slightly compacted powders of lead azide over a wide range of laser pulse length," Combustion, Explosion and Shock Waves, vol. 44, no. 5, pp. 583-585, 2008.

[6] A. V. Khaneft and E. V. Duginov, "Effect of melting on the critical ignition energy of condensed explosives by a short laser pulse," Combustion, Explosion and Shock Waves, vol. 48, no. 6, pp. 699-704, 2012.

[7] V. N. Vilyunov and V. E. Zarko, Ignition of Solids, Elsevier, Amsterdam, The Netherlands, 1989.

[8] A. M. Grishin, A. N. Golovanov, and V. V. Medvedev, “On the ignition of a layer of combustible forest materials by light radiation," Combustion, Explosion and Shock Waves, vol. 35, no. 6, pp. 618-621, 1999.

[9] R. S. Burkina, E. Y. Morozova, and V. P. Tsipilev, "Initiation of a reactive material by a radiation beam absorbed by optical heterogeneities of the material," Combustion, Explosion and Shock Waves, vol. 47, no. 5, pp. 581-590, 2011.

[10] G. V. Kuznetsov and P. A. Strizhak, "3D problem of heat and mass transfer at the ignition of a combustible liquid by a heated metal particle," Journal of Engineering Thermophysics, vol. 18, no. 1, pp. 72-79, 2009.

[11] P. Dagaut and M. Cathonnet, "The ignition, oxidation, and combustion of kerosene: a review of experimental and kinetic modeling," Progress in Energy and Combustion Science, vol. 32, no. 1, pp. 48-92, 2006.

[12] R. S. Burkina and E. A. Mikova, "High-temperature ignition of a reactive material by a hot inert particle with a finite heat reserve," Combustion, Explosion and Shock Waves, vol. 45, no. 2, pp. 144-150, 2009.

[13] Y. B. Zeldovich, G. I. Barenblatt, and G. M. Makhviladze, The Mathematical Theory of Combustion and Explosions, Plenum, New York, NY, USA, 1985.

[14] O. V. Vysokomornaya, G. V. Kuznetsov, and P. A. Strizhak, "Numerical analysis of heat-mass transfer mechanisms in gasphase ignition of films of liquid condensed substances by a laser beam," Journal of Engineering Thermophysics, vol. 19, no. 2, pp. 85-93, 2010.

[15] G. V. Kuznetsov and P. A. Strizhak, "Gas-phase ignition of a film of liquid condensed substance by a metal particle heated to high temperatures under mixed-convection conditions," Journal of Engineering Physics and Thermophysics, vol. 82, no. 6, pp. 10661072, 2009.

[16] G. V. Kuznetsov and P. A. Strizhak, "Transient heat and mass transfer at the ignition of vapor and gas mixture by a moving hot particle," International Journal of Heat and Mass Transfer, vol. 53, no. 5-6, pp. 923-930, 2010.

[17] D. O. Glushkov and P. A. Strizhak, “Transient heat and mass transfer of liquid droplet ignition at the spreading over the heated substrate," Advances in Mechanical Engineering, vol. 2014, Article ID 269321, 9 pages, 2014.

[18] A. A. Samarskii, The Theory of Difference Schemes, Marcel Dekker, New York, NY, USA, 2001.

[19] N. B. Vargaftik, L. P. Filipov, A. A. Tarzimanov, and E. E. Totskii, Handbook of Thermal Conductivity of Liquids and Gases, CRC Press, Boca Raton, Fla, USA, 1994.

[20] J. O. Hirschfelder, C. F. Curtiss, and R. B. Bird, Molecular Theory of Gases and Liquids, John Wiley \& Sons, New York, NY, USA, 1954. 
[21] J. House, Principles of Chemical Kinetics, Academic Press, New York, NY, USA, 2007.

[22] V. Patel, Chemical Kinetics, InTech, Rijeka, Croatia, 2012.

[23] P. Deb, Kinetics of Heterogeneous Solid State Processes, Springer, New York, NY, USA, 2014. 


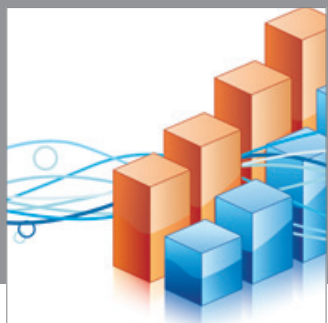

Advances in

Operations Research

mansans

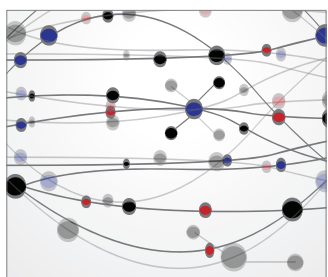

The Scientific World Journal
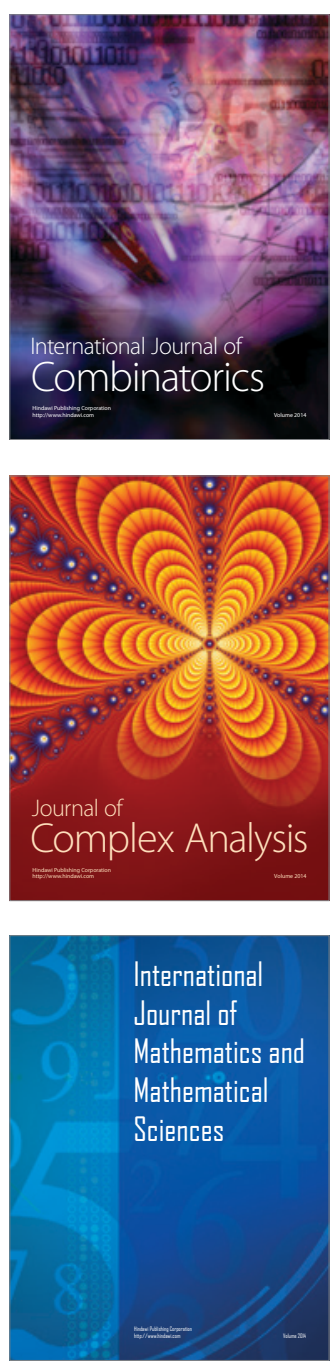
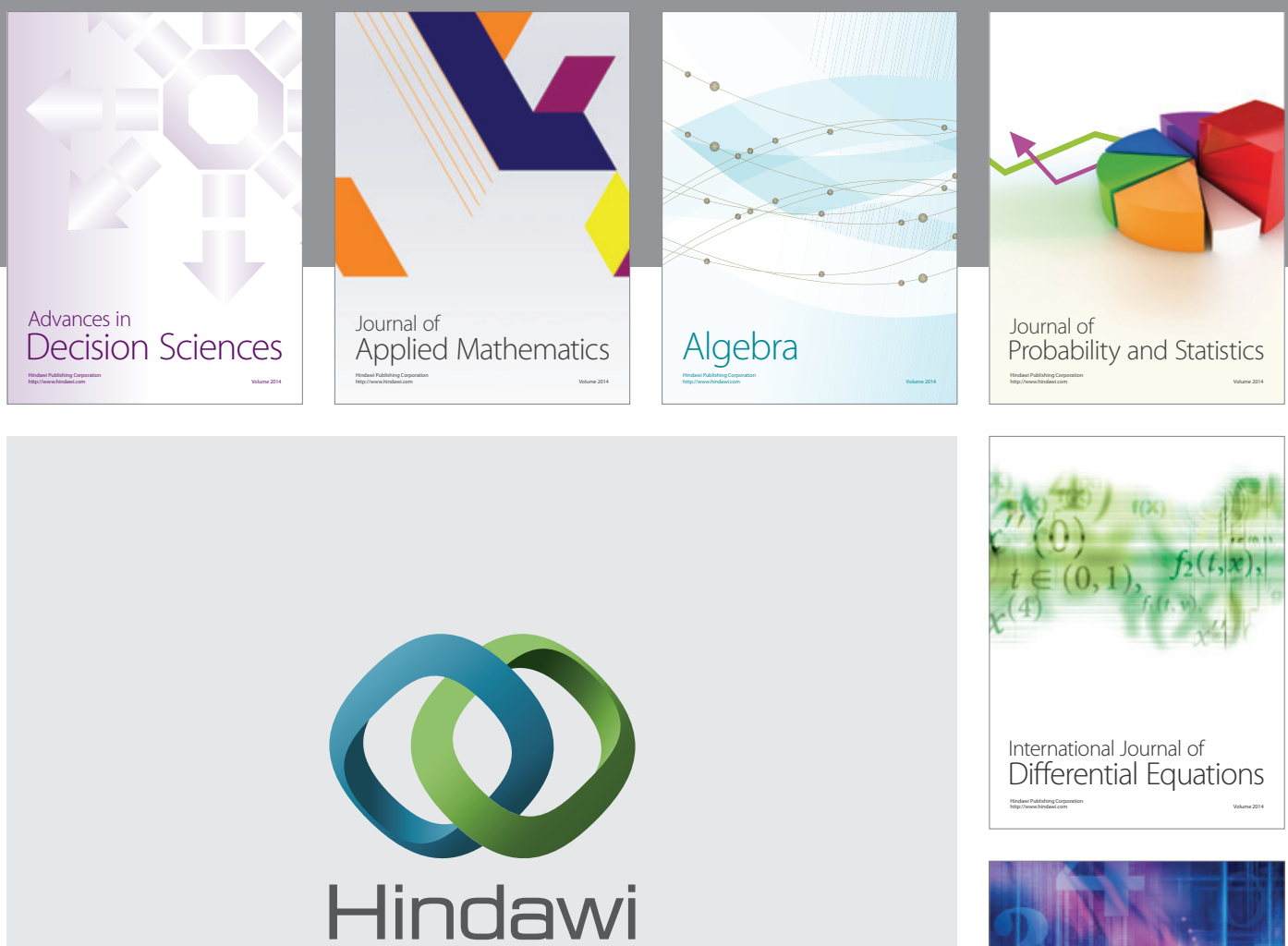

Submit your manuscripts at http://www.hindawi.com
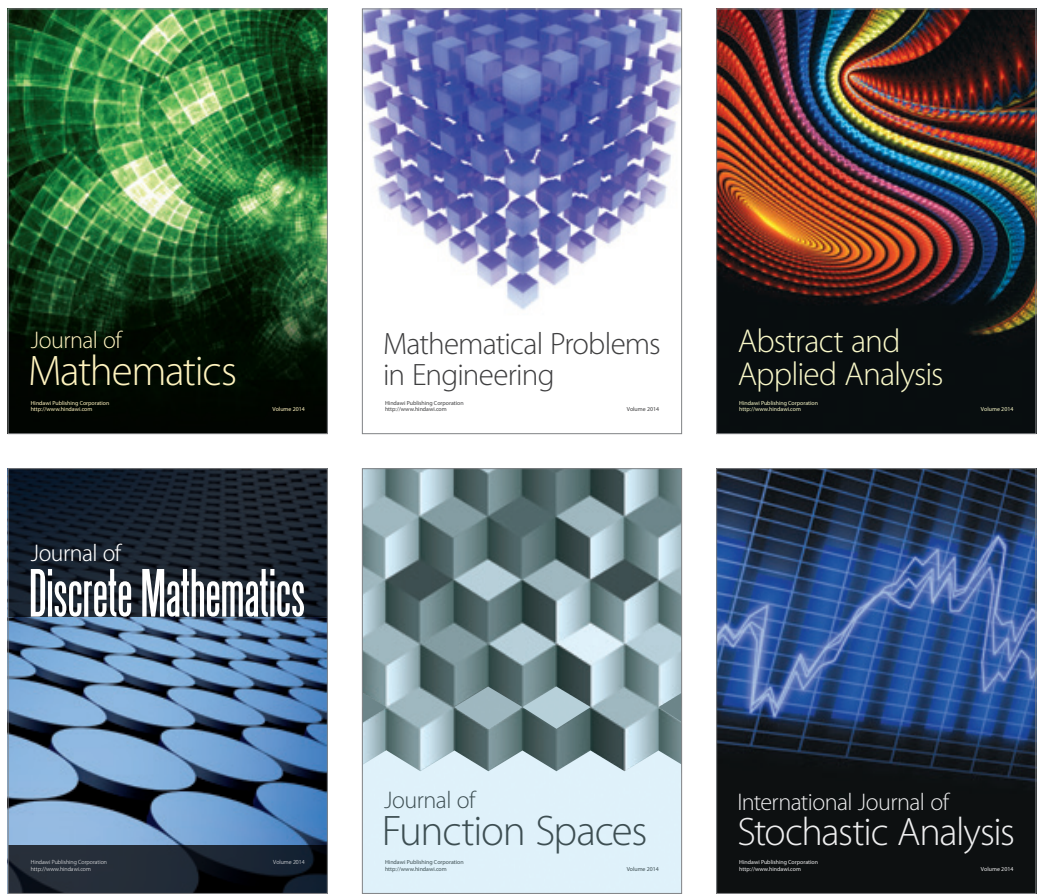

Journal of

Function Spaces

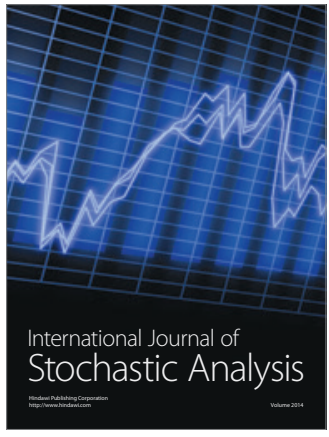

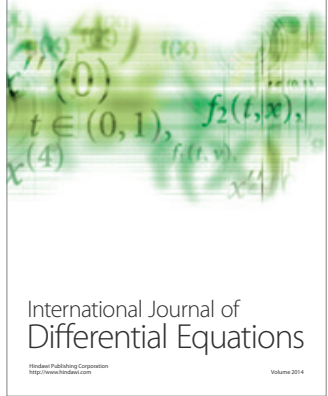
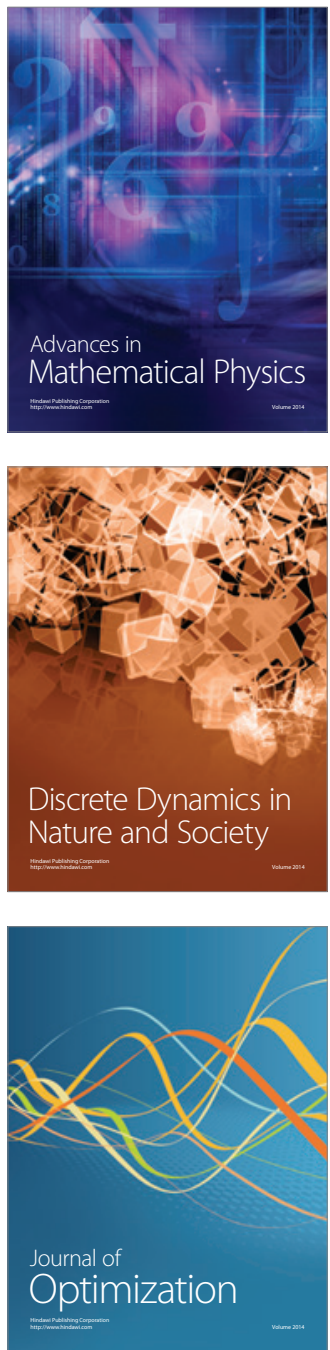